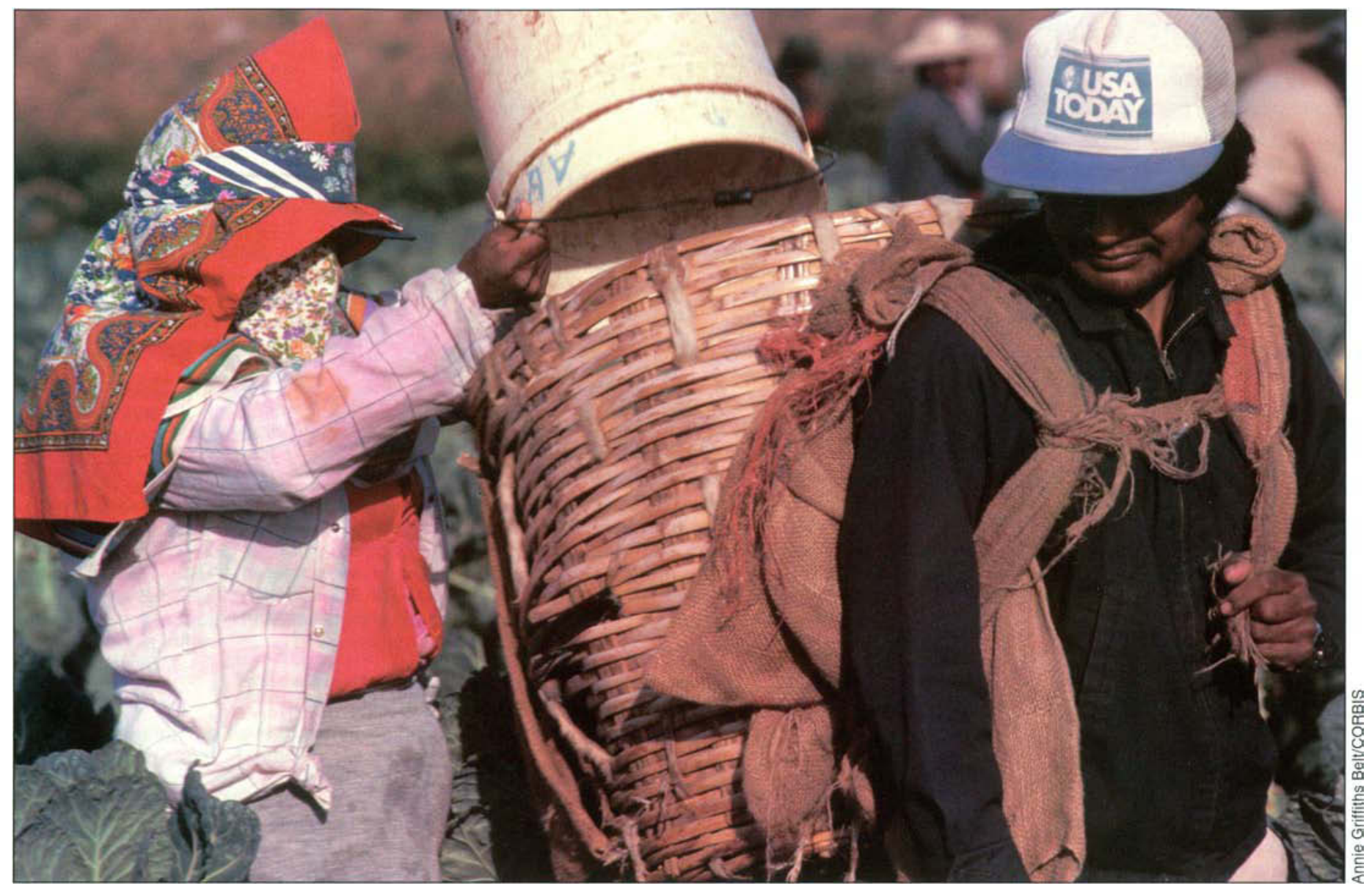

Between 1980 and 1997 , the import share of fresh vegetables has doubled from $5 \%$ to $10 \%$ in the United States, allowing year-round availability for consumers. In Baja, Mexico, workers harvest brussels sprouts.

\title{
Global surveillance needed to prevent foodborne disease
}

\section{Craig W. Hedberg}

In the interest of improving their diet and health, consumers have increased their demand for fresh fruits and vegetables. Meeting this demand has stimulated worldwide trade in fresh produce. Several highly publicized outbreaks of foodborne disease highlight the risks of fresh produce being contaminated during growing, harvesting, processing or transportation. These outbreaks have included domestic as well as imported produce. However, two factors - the challenge of impiementing and maintaining good agricultural practices in developing countries, and the potential for produce contamination with exotic microorganisms that can cause foodborne disease - raise special concerns about the safety of imported produce. Investigating outbreaks of foodborne disease can identify new foodborne disease hazards and lead to new strategies to prevent and control them. A strong system of publichealth surveillance for foodborne disease provides a foundation for risk management of worldwide food distribution.
"We Americans are eating more imported food than ever, more than double the amount we consumed just 7 years ago. Any food that fails to meet clear and strict standards for safety should not make it to the marketplace; it's just that simple."

- President Clinton's radio address to the nation, Dec. 11, 1999.

O ur diets are constantly changing. Since the early 1970s, publichealth professionals have been exhorting us to reduce the amount of fat we eat and increase consumption of fresh fruits and vegetables. From heart disease to cancer, the medical literature 
has exploded with publications confirming the benefits of a diet rich in whole grains and fresh fruits and vegetables. The National Cancer Institute has stepped beyond traditional health education into a successful publichealth marketing effort with its " 5 a Day-for Better Health" campaign. While most of us still do not consistently achieve this goal, we have created a demand for year-round availability of fresh produce that has transformed the industry and created new safety challenges.

Never before have we had such an abundant and varied supply of fresh fruits and vegetables. No longer do we allow our main produce items to go "out of season." We "follow the sun" and import them from where they are in season. Unfortunately, many fresh fruits and vegetables are field-grown commodities with inherent risks for contamination by the parasites, bacteria and viruses (collectively called foodborne pathogens) that cause foodborne illness. Many of these fresh fruits and vegetables are also ready-toeat foods, some are processed for convenience such as bags of salad or carrot sticks. To complicate matters, these foodborne pathogens can penetrate into the interior tissues of many fresh produce items (Tauxe et al. 1997), where they are protected from our efforts to wash off or kill them with sanitizers.

How can we evaluate and manage the risks of foodborne disease that come with the worldwide food distribution needed to meet growing demands? How can we begin to develop the "clear and strict standards for safety" called for by President Clinton?

\section{Our changing diets}

Diets change in response to the price of foods, societal tastes, crowded personal and professional schedules, and concerns about health. During the mid-1970s, the United States experienced OPEC-driven gas shortages and soaring prices due to inflation. Because food and produce prices also rose, consumption of fresh fruits and vegetables declined $6 \%$ from 1970 to 1974 (Putnam and Allshouse 1999). In
1982, the National Academy of Sciences published Diet, Nutrition and Cancer. This report, which served as the forerunner for the 5-a-day campaign, stimulated annual increases in demand for fresh fruits and vegetables, which continues today (fig. 1).

U.S. residents currently eat $24 \%$ more fresh fruits and vegetables than they did in 1982 , and enjoy the relatively cheapest food supply in the world, spending only about $11 \%$ of disposable income on food. Also, in absolute terms, we spend less on food than consumers in any other major developed country. Because food is relatively inexpensive in the United States, small increases in the costs of fresh fruits and vegetables have not historically reduced demand. But the price of fresh produce still matters. From 1970 to $1997,21 \%$ of the variability in annual levels of fruit consumption was due to changes in price (fig. 2).

As grocery stores continue to increase in size, produce departments are growing too. The median grocery store is now more than 40,000 square feet, almost $13 \%$ of which is occupied by the produce department. Produce accounts for $11 \%$ of grocery store sales, but $18 \%$ of profits (Food Marketing Institute 2000). The strong U.S. economy and the profitability of fresh produce has led to the introduction and increased availability of a wide variety of produce items, from kiwifruit, mangoes and papayas, to alfalfa sprouts, specialty lettuces and freshcut, packaged produce.

Consumer response to these new products can be seen in a survey of residents of seven states participating in the Centers for Disease Control and Prevention's (CDC) FoodNet Active Surveillance Program for foodborne diseases. Nineteen percent of respondents reported eating a mesclun lettuce mix (tender young greens such as
A National Cancer Institute educational campaign encourages produce consumption to reduce the risk of illnesses such as heart disease and cancer.

arugula and chickory) in the 7 days before the interview and $8 \%$ reported eating alfalfa sprouts. However, eating habits are highly regional. For example, in California, $29 \%$ of respondents ate mesclun lettuce and $11 \%$ ate alfalfa sprouts. In Minnesota, only $14 \%$ ate mesclun lettuce and less than $8 \%$ ate alfalfa sprouts (CDC 1999a).

Fresh produce has also become a mainstay of restaurant fare, where we now spend $45 \%$ of food dollars. Dinner salads and salad bars have become

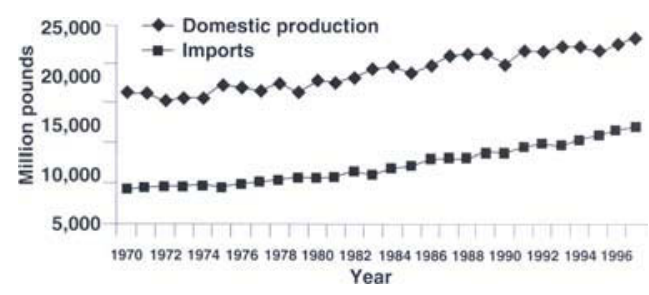

Fig. 1. Domestic production and imports of fresh fruits, United States, 1970-1997.

Source: USDA Economic Research Service.

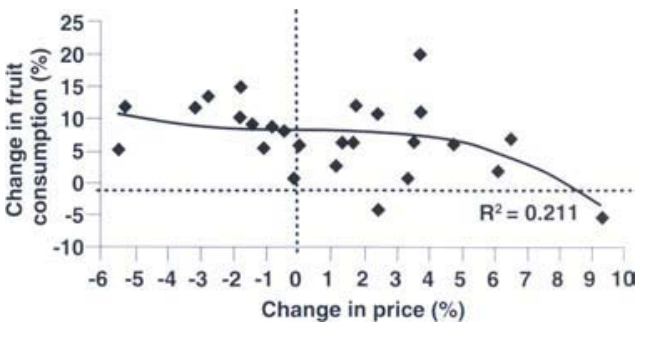

Fig. 2. Effect of price changes on fresh fruit consumption, United States, 19701997. Source: USDA Economic Research Service. 


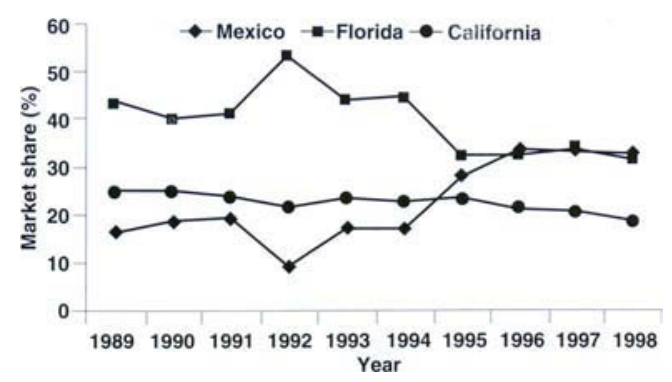

Fig. 3. Fresh tomato market share, United States, 1989-1998. Source: USDA Agricultural Marketing Service.

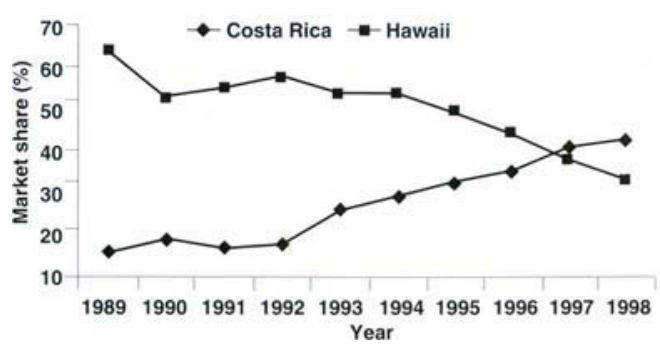

Fig. 4. Fresh pineapple market share, United States, 1989-1998. Source: USDA Agricultural Marketing Service.

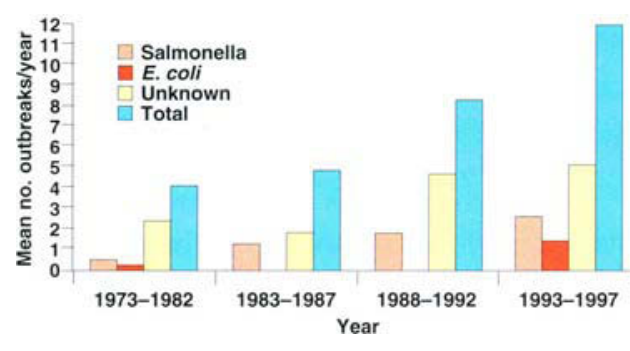

Fig. 5. Confirmed foodborne outbreaks associated with fresh fruits and vegetables, United States, 1973-1997. Source: Centers for Disease Control and Prevention.

mainstream. In addition, ethnic cuisines - such as Chinese, Mexican, Thai and Middle Eastern - that feature fresh produce ingredients are becoming increasingly popular.

Despite encouraging trends in the consumption of fresh fruits and vegetables, a recent study demonstrated that only $17 \%$ of Americans ate five or more servings of fresh fruits and vegetables per day (Thompson et al. 1999). We are likely to see continued publichealth marketing campaigns to increase fruit and vegetable consumption for years to come.

\section{Globalization of the food supply}

Not only has the variety of fresh fruits and vegetables increased in re- cent years, but we have also increased their year-round availability; both increases are due, in part, to imported produce. From 1980 to 1997 , the import share of fresh vegetables doubled from $5 \%$ to $10 \%$. The import share of tomatoes increased from $22 \%$ to $32 \%$. The timing of growing seasons put Mexican tomatoes in direct competition with Florida for market share (fig. 3). From 1989 through 1998, the market share of Mexican tomatoes increased from $17 \%$ to $33 \%$, while Florida tomatoes declined from $44 \%$ to $32 \%$. Import markets have developed for salad greens, such as romaine lettuce and spinach (Long and Edwards 1999).

Similarly, the import share of fresh fruits increased from $24 \%$ to $34 \%$ during this time period. The import share of cantaloupes rose from $13 \%$ to $29 \%$ and limes jumped from $43 \%$ to $95 \%$. During the 1990s, Guatemalan growers developed export markets for raspberries and blackberries, filling a brief gap between the winter harvest of raspberries in Chile and the summer harvest of raspberries in California. In 1997, Hawaii was replaced by Costa Rica as the largest supplier of fresh pineapple for the United States (Long and Edwards 1999) (fig. 4). Mexico is now second only to California in producing fresh fruits and vegetables for U.S. markets.

The reasons behind the increasing globalization of fresh produce are many and varied. Many tropical fruits have restricted growing ranges. International treaties such as NAFTA and GATT have reduced import barriers. Land, labor and materials are cheaper in many developing countries. The strength of the U.S. dollar relative to foreign currencies has further reduced the costs of imports. Tropical production areas can be harvested when temperate areas are out of production. Commercial varieties of fruits and vegetables can be picked at a "mature green" stage and ripened during shipping. Finally, growers in many developing countries may not have to adhere to the same labor, environmental and food safety standards as U.S. growers. It is this final point that drives the concern expressed by Presi-
As new foods and sources of foods become available, opportunities for foodborne disease transmission by new or exotic pathogens often follow.

dent Clinton at the top of this article, and is one of the major factors that must be considered in risk management for the worldwide distribution of fresh produce: what special considerations must be made to implement and maintain good agricultural practices (GAPs) in developing countries? In many developing countries, basic infrastructure such as sanitary waste disposal and safe water supplies may not exist.

Our reliance on imported produce will only increase during the coming years, and this should be good for consumers. We will benefit from an abundant, varied and affordable supply of fresh fruits and vegetables. However, as new foods and new sources of foods become available, opportunities for foodborne disease transmission by new or exotic pathogens often follow. Cantaloupes hauled in open trucks in Mexico have been contaminated by Salmonella in the ice used to cool them. As fresh produce is transported over greater distances and time, contaminated shipping containers and inadequate refrigeration will be become increasingly important as potential hazards.

The development of export production of raspberries in Guatemala led to widespread outbreaks of diarrheal illnesses caused by the parasite $\mathrm{Cyclo-}$ spora cayetanensis in the United States and Canada in 1996 and again in 1997 (Herwaldt et al. 1997). To guard against such importations of "travelers' diarrhea," we must expand and improve our efforts to monitor both the quality of produce and the health of people eating it. Effective foodborne disease surveillance is important, because despite all of our best efforts to prevent foodborne diseases, humans remain the ultimate bioassay for low- 
level or sporadic contamination of our food supply. In addition, what we learn from outbreak investigations can help us identify new hazards, such as Cyclospora in Guatemalan raspberries, and be more effective at preventing outbreaks from known sources, such as Salmonella on cantaloupe.

\section{Outbreaks and fresh produce}

In recent years, the number and proportion of outbreaks of foodborne illness associated fresh fruits and vegetables have increased. For example, $21(20 \%)$ of 107 confirmed foodborne outbreaks reported in Minnesota from 1981 through 1989 were associated with fresh produce. From 1990 through $1998,54(29 \%)$ of 188 outbreaks were due to produce. Approximately $60 \%$ of these were outbreaks due to Norwalk-like viruses (NLV), a group of viruses that cause an illness with vomiting and diarrhea that many would recognize as "stomach flu." However, CDC estimates that NLVs cause two-thirds of all foodborne illnesses that have a known cause (Mead et al. 1999). Many NLV outbreaks have occurred in restaurants where ill food workers contaminated the produce they handled. While food workers may bring viruses or bacteria into the restaurant as a result of getting sick outside of work, they also may eat the same contaminated foods that patrons eat. A shipment of contaminated produce could cause an outbreak at a restaurant; if food workers get infected they could amplify the contamination and cause a larger outbreak.

This is what apparently happened in Minnesota during recent outbreaks of Shigella sonnei and enterotoxigenic Escherichia coli from contaminated parsley. These outbreaks indicate a need to reduce barehanded contact with ready-to-eat foods, improve hand-washing and personal hygiene practices, and create incentives for ill employees to stay away from work. In addition to the outbreaks in which food workers caused or amplified the outbreak, Minnesota also experienced two outbreaks of Salmonella from contaminated tomatoes, an outbreak of Salmonella from contaminated cantaloupe, and an outbreak of unknown etiology

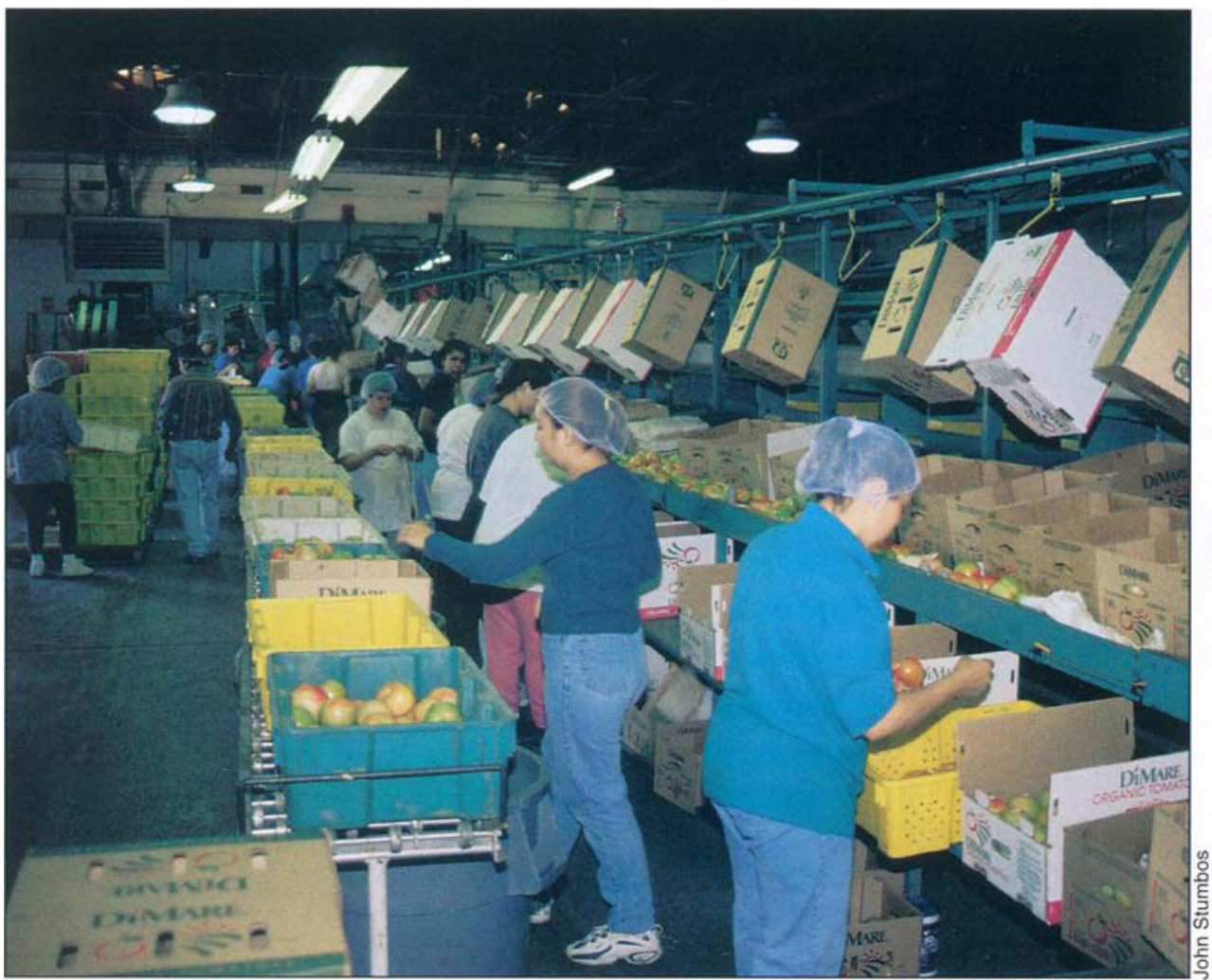

associated with fresh pineapple imported from Costa Rica.

On the national level, 164 foodborne outbreaks due to fresh produce (excluding salads) were reported to $\mathrm{CDC}$ from 1973 to 1997 (Tauxe et al. 1997; Bean et al. 1996; Olsen et al. 2000). The mean number of produce-associated outbreaks nearly tripled from 4.0 per year from 1973 through 1982 to 11.8 per year from 1993 through 1997 (fig. $5)$. Over these time periods, the mean number of fresh produce outbreaks due to Salmonella increased more than sixfold, and outbreaks caused by various $E$. coli went from rare to regular occurrences. In addition to outbreaks associated with specific fruit and vegetable items, there were 202 outbreaks associated with salads. Two-thirds of these were caused by unknown agents, very likely Norwalk-like viruses.

Although most of the 76 million foodborne illnesses that occur each

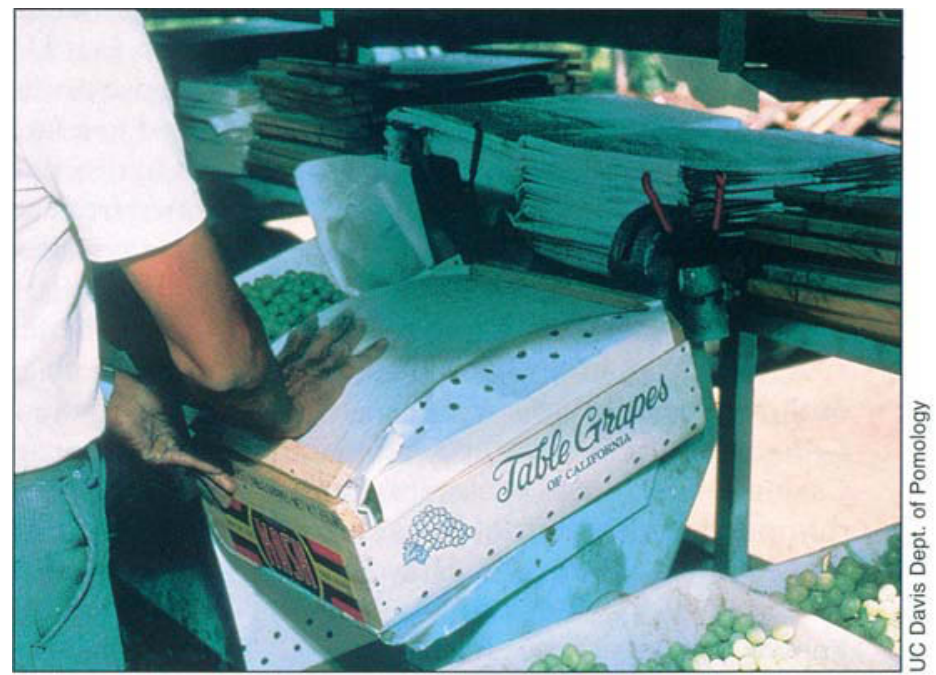

Fruits and vegetables are grown outdoors in fields where they are at risk of contamination by illness-causing organisms. Postharvest processing and handling may also increase risks.

year in the United States cause mild gastrointestinal symptoms (such as cramps, diarrhea and vomiting) for 1 to 3 days, some (notably E. coli 0157:H7 and Listeria monocytogenes) can cause serious illness, particularly for the very young, the elderly, pregnant women and persons with weakened immune systems. Each year in 


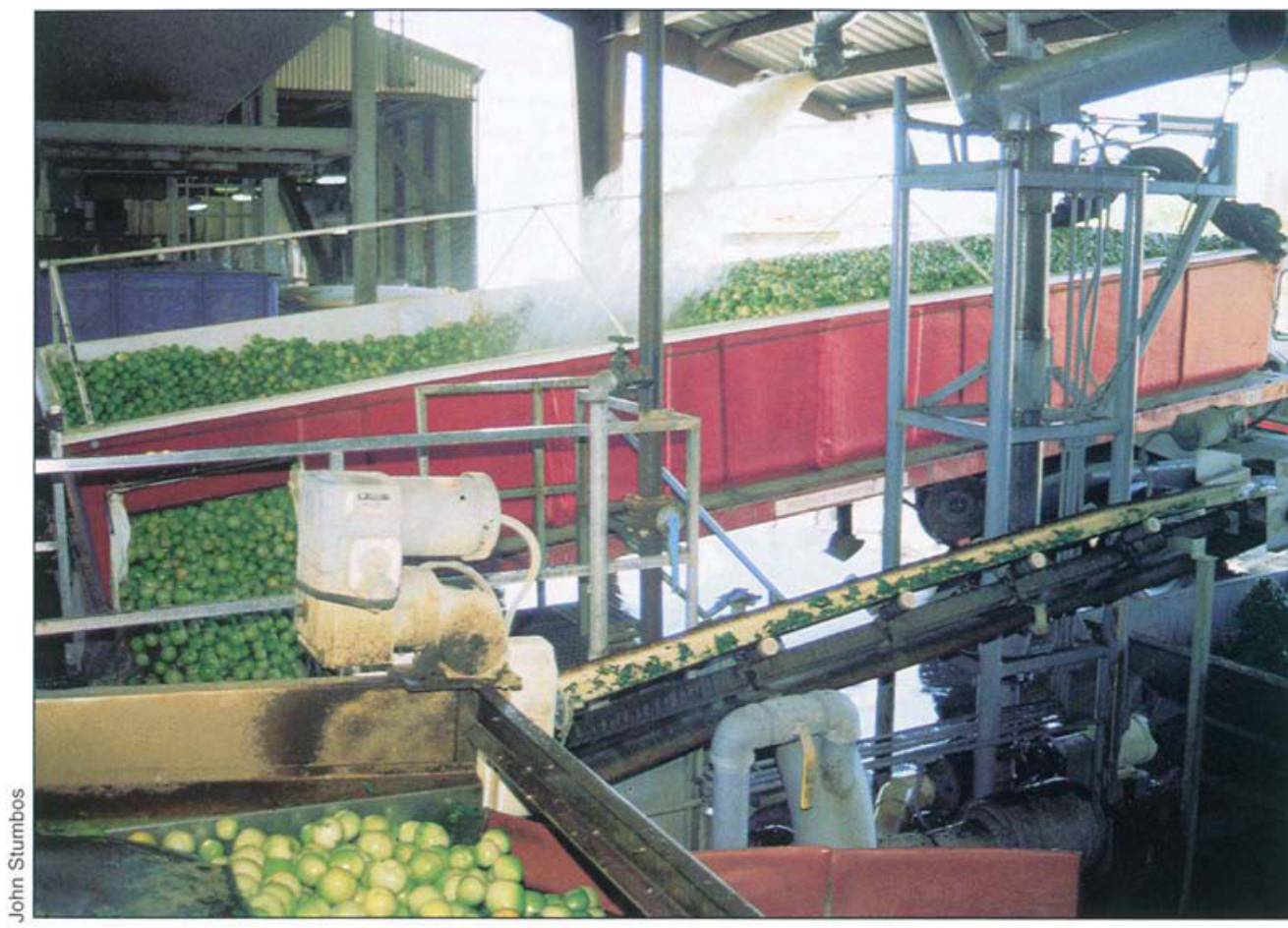

the United states, an estimated 325,000 people are hospitalized, and 5,000 people die from foodborne diseases (Mead et al. 1999).

\section{Sources of contamination}

Contamination of fresh fruits and vegetables with foodborne pathogens can occur in many ways (table 1 ). In 1990, and again in 1993, multistate outbreaks of Salmonella were caused by tomatoes from one shipper in South Carolina. Harvested tomatoes were dumped into a water tank that was inadequately chlorinated. How Salmonella got into the dump tank is unknown. However, once it was contaminated, the tank likely served as a source for spreading Salmonella to many of the tomatoes dumped into it (Hedberg et al. 1999).

In 1996, an outbreak of E. coli 0157:H7 in Connecticut and Illinois was caused by mesclun lettuce that was produced by a single growerprocessor in California (Hilborn et al. 1999). Cattle were being raised near the lettuce fields. Wash water and finished lettuce samples had evidence of fecal contamination. Runoff from cattle manure appeared to contaminate the untreated water used in the lettuce processing.
In 1998, outbreaks of $S$. sonnei infection in four U.S. states and two Canadian provinces were caused by parsley traced to a farm in Mexico. Water used in a hydrocooling operation was being drawn from an untreated municipal water system, which may have been contaminated with human sewage (CDC 1999b). In these and other outbreaks, such as those due to Cyclospora contamination of Guatemalan raspberries, water used in growing, harvesting or processing the produce was the probable source of contamination.

These outbreaks point out that many sources of foodborne pathogens - whether human, animal or environmental - can directly contaminate water, and thereby indirectly contaminate fresh fruits and vegetables. Therefore, water quality is a key ingredient to ensuring food safety.

Outbreaks associated with unpasteurized apple and orange juices highlight another concern. Contamination of individual whole fruits can cause large outbreaks if they are processed and combined in large quantities. For example, apples may be contaminated with soil or animal feces when they fall to the ground. The use of such "dropped" fruit may have led to the $E$. coli O157:H7 contamination of

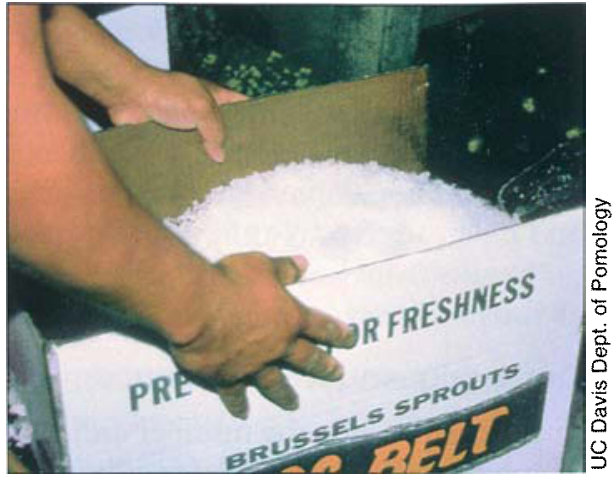

Left, above and right, Water - such as that used for growing, harvesting, cleaning and processing - is sometimes the root-cause of foodborne illness outbreaks.

Odwalla apple juice in 1996 (Cody et al. 1999). Thus, "one bad apple can spoil the whole bunch." In addition to juice production, chopping and mixing - such as happens in fresh-cut produce operations - can create the same potential for amplifying contamination from a single item to a whole batch. This effect likely was important to the occurrence of outbreaks of Shigella involving parsley, and in outbreaks of Salmonella involving cantaloupe and tomatoes.

Finally, the contamination of alfalfa seed with Salmonella and E. coli 0157:H7 represents the worst-case scenario for fresh produce. From 1994 through 1998, 12 multistate or international outbreaks were caused by alfalfa or other small seed sprouts (Taormina et al. 1999). The conditions needed to germinate the seeds and grow sprouts - damp, warm environments - are also ideal conditions to grow the bacteria. The smallest of contamination events can result in highly contaminated finished product.

As a result of these outbreak investigations and applied research to better understand how contamination occurs and can be controlled, GAPs have been developed for a number of produce commodities, such as unpasteurized cider and fresh juices, fresh-cut produce, sprouts and melons. In addition to the efforts of individual producers, guides to minimize microbial food-safety hazards for produce have been developed by industry associa- 


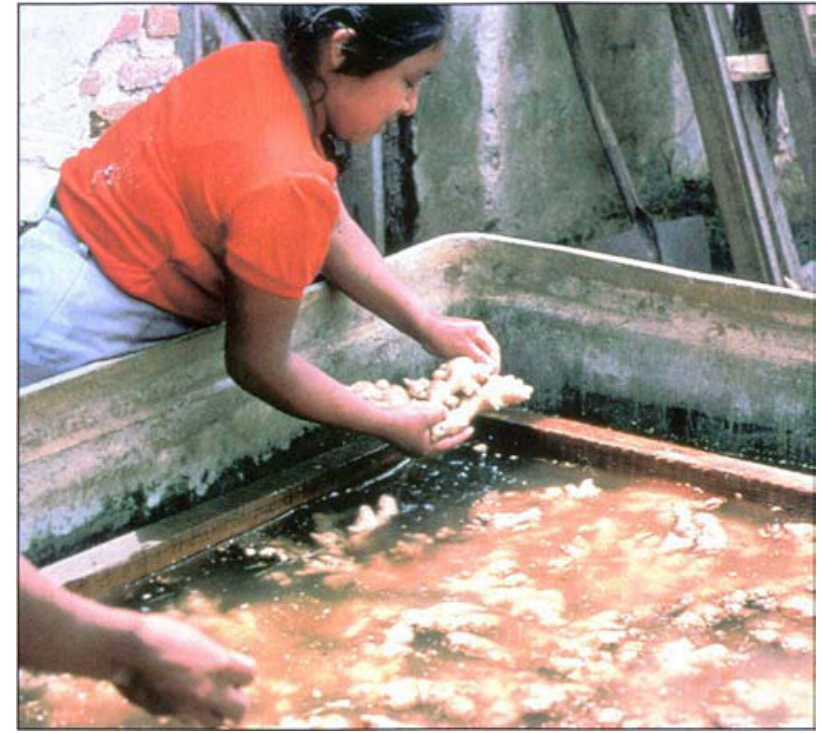

tions and the U.S. Food and Drug Administration (FDA 1998).

\section{Public-health surveillance}

Food safety is a product of many environmental, cultural and socioeconomic factors. Epidemiologic methods of foodborne disease surveillance are needed to detect outbreaks, identify their causes and assess the effectiveness of control measures. Risk management necessarily follows a process of risk assessment. These are the principles behind hazard analysis and critical control point (HACCP) systems for protecting the safety of foods. Many foodborne hazards, either in terms of specific foodborne pathogens or food ingredients, were originally identified as a result of foodborne disease surveillance. Because food sources and foodborne disease agents are constantly changing, hazard analysis is an ongoing process that requires continuous support for public-health surveillance of foodborne diseases.

Foodborne disease surveillance has historically been a passive process conducted by state and local health departments. It has relied on individuals to recognize that they may have been part of an outbreak, or to be sufficiently ill and motivated to seek medical care. Beyond this, it requires a physician to obtain a stool culture, a laboratory to identify the cause of the illness, and finally, the physician to report the illness to the health department. Each of these steps reduces the sensitivity of our surveillance to the extent that only a small percentage of foodborne illnesses ever get reported. For common and well-known diseases such as salmonellosis, it is estimated that 38 cases occur for every one reported. For others, such as enterotoxigenic E. coli (ETEC), a common cause of "travelers' diarrhea," there is no effective surveillance because clinical laboratories cannot identify it.

FoodNet. The Clinton administration's National Food Safety Initiative includes several efforts to improve the surveillance of foodborne diseases. Launched in 1995, FoodNet is a multistate active surveillance network designed to provide populationbased surveillance for several major foodborne pathogens, such as Salmonella and E. coli O157:H7. Through a combination of surveys and special studies, it is also designed to provide context for better understanding how much foodborne illness actually occurs, and how much of it may be attributable to specific food items such as ground beef or alfalfa sprouts. In addition, FoodNet is the primary source for the recent estimate that 76 million foodborne illnesses occur each year in the United States (Mead et al. 1999).
PulseNet. A second major initiative, and the one that will have the greater impact on foodborne disease surveillance, is the National Molecular Subtyping Network (PulseNet). Initiated in 1995 by CDC in collaboration with state public health laboratories and the USDA, PulseNet takes advantage of the combined revolutions in molecular biology and information. technology. PulseNet uses a technique called pulsed-field gel electrophoresis (PFGE) to distinguish specific subtypes among relatively common organisms, such as E. coli O157:H7 and $S$. typhimurium. These PFGE patterns can be sent over the Internet from one laboratory to another. For example, an outbreak of E. coli O157:H7 infections in Colorado was associated with consumption of a nationally distributed ground beef product (CDC 1997). Within days, it was possible to compare the outbreak strain to PFGE patterns of E. coli O157:H7 isolates in other states. This gives PulseNet the potential to provide the backbone for a public-health surveillance system that can offer truly national surveillance for foodborne diseases.

Molecular subtyping by PFGE was instrumental in linking $E$. coli O157:H7 outbreaks in Connecticut and Illinois, which led to the identification of mesclun lettuce as the source of the outbreak. It also allowed apparently independent outbreaks of S. sonnei infections across the United States and Canada to be linked. Although the independent investigations did not identify the cause, the linkage of the out-

TABLE 1. Primary contamination sources and foodborne disease concerns associated with fresh fruits and vegetables

\begin{tabular}{ll}
\hline \hline Contamination source & \multicolumn{1}{c}{ Foodborne disease concern* } \\
\hline $\begin{array}{l}\text { Water used in irrigation, harvesting or processing } \\
\text { contaminated with animal feces }\end{array}$ & $\begin{array}{l}\text { E. coli O157: } \mathrm{H7} \text {, Salmonella, Campylobacter, } \\
\text { Cryptosporidium, Yersinia }\end{array}$ \\
$\begin{array}{l}\text { Water used in irrigation, harvesting or processing } \\
\text { contaminated with human feces }\end{array}$ & $\begin{array}{l}\text { Shigella, enterotoxigenic E. coli, Norwalk-like } \\
\text { viruses, hepatitis A virus, Cryptosporidium, }\end{array}$ \\
$\begin{array}{l}\text { Environmental contamination during processing, } \\
\text { transportation, or service }\end{array}$ & $\begin{array}{l}\text { Listeria monocytogenes, Salmonella, } \\
\text { Campylobacter, E. coli O157:H7 }\end{array}$ \\
Infected food handlers & $\begin{array}{l}\text { Shigella, enterotoxigenic E. coli, Norwalk-like } \\
\text { viruses, hepatitis A virus, E. coli O157:H7, } \\
\text { Salmonella, Cryptosporidium, Giardia }\end{array}$ \\
\hline
\end{tabular}

* This list is not intended to be comprehensive. Additional foodborne disease concerns are likely to exist within each of these contamination sources. The Centers for Disease Control and Prevention estimates $82 \%$ of foodborne illnesses are caused by pathogens that have not yet been identified. 


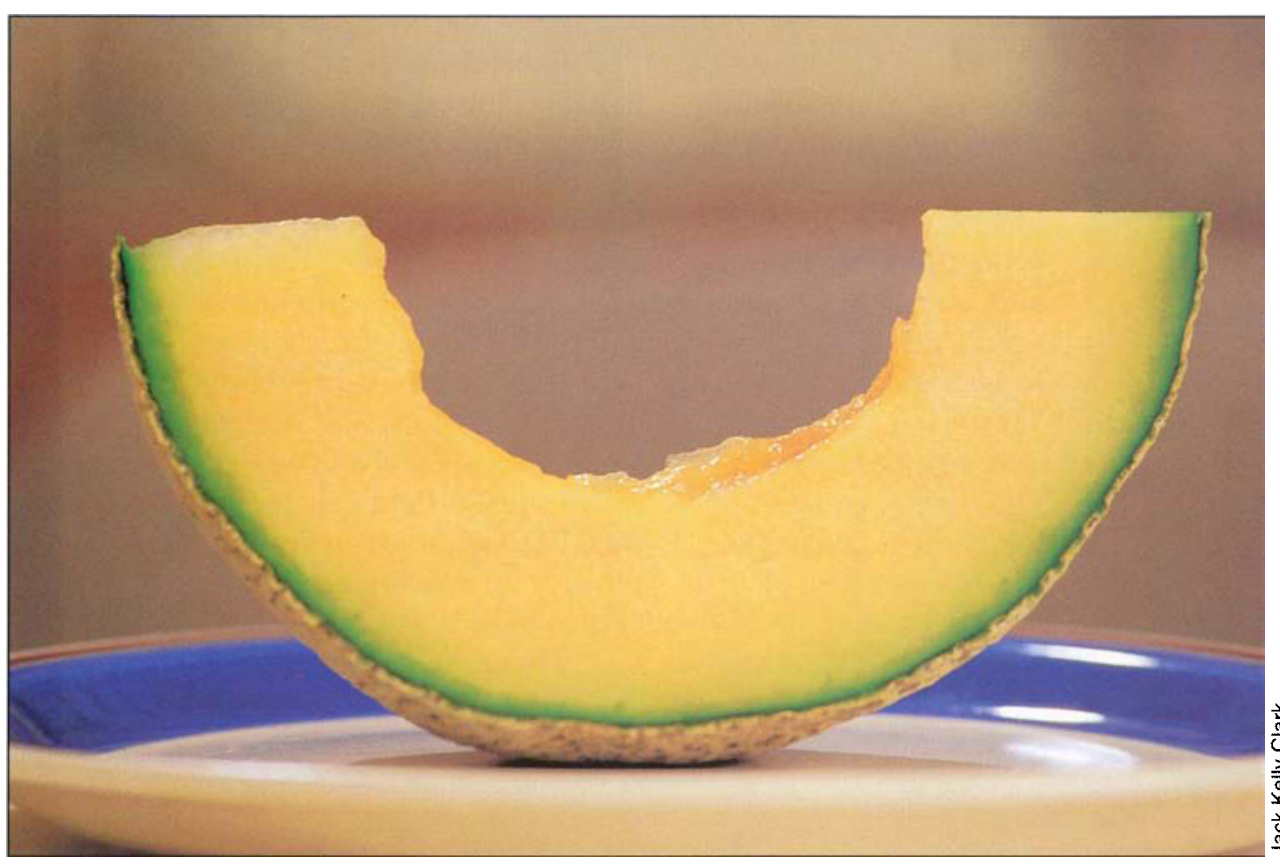

Risk assessments are needed to evaluate potential sources of produce contamination and identify appropriate risk-management techniques, such as good agricultural practices, HACCP, irradiation or pasteurization.

breaks allowed investigators to identify the common source - parsley that had been imported from Mexico.

These efforts to enhance surveillance can also be linked with systematic efforts to collect and evaluate consumer complaints about restaurants and food products. In Minnesota, consumer complaints have been linked to identify outbreaks in restaurants before individual cases were reported from physicians. The California Department of Health Services investigates more than 6,000 consumer complaints on an annual basis. These complaints serve as sentinel events of food safety failures, and help prevent contaminated food products from reaching a larger market.

Risk assessment. Risk assessments for specific pathogens such as Shigella in imported parsley, Salmonella in cantaloupe or tomatoes, or E. coli O157:H7 in lettuce, as with Salmonella enteritidis in shell eggs, require making measurements or assumptions about many parameters. At every step from farm to table, potential sources of contamination can be identified, measured and modeled to determine the relative contribution to the overall risk of foodborne disease occurring.

For many foodborne pathogens of public-health importance, contamina- tion of the finished product is a very sporadic to rare occurrence. Microbiological testing may be an appropriate tool to validate a control point in a HACCP system, but end-product testing is hard to justify as a prevention measure. Given the scale of modern agriculture and food production systems, contamination levels below the statistical and microbiological threshold can still be large public-health problems. For example, internal contamination of eggs with $S$. enteritidis is rare; about 1 in 20,000 eggs on a national basis in the United States, with a range from 2.5 to 62.5 per 10,000 eggs from environmentally positive flocks. Despite this sporadic occurrence, shell eggs or foods made with shell eggs accounted for $137(36 \%)$ of 380 outbreaks of $S$. enteritidis infections reported to CDC from 1985 through 1991 (Hogue et al. 1997). Similarly, contamination of fresh fruits and vegetables during production, harvesting, processing or transportation is a sporadic occurrence. Yet even with sporadic contamination, the increasing consumption of fresh produce makes it a growing public-health concern.

Importantly, the population itself is changing. As the population ages, the number and proportion of people at high risk for serious complications of foodborne illnesses will increase. Even if the risk of foodborne illnesses remains constant, the public-health burden of those illnesses will increase. Identifying factors that contribute to the occurrence of outbreaks and identifying ways to control and monitor them will become increasingly important.

\section{Future in focus: Improved risk management}

As worldwide food distribution expands, outbreaks of foodborne disease are likely to continue. During the next 25 years, we will see a growing variety of apparently new and emerging pathogens associated with these outbreaks. The parasites, bacteria and viruses that cause diarrheal illnesses among children in developing countries will be one major group of these emerging foodborne diseases. Diseases of animals used for food production will be a second major group. It was only 25 years ago that Cryptosporidium was considered a veterinary problem for cattle. Now it is recognized as an important cause of human illness that can be transmitted by contaminated food and water. Most dramatically, in 1993, 400,000 residents of Milwaukee, Wis., became ill after the city water supply was contaminated (Mac Kenzie et al. 1994).

As new areas are opened up to agricultural production, many of the risks associated with potential human, animal and environmental sources of foodborne diseases in these areas will not be fully known. New hazards associated with production, harvesting, processing and transportation will occur. As these developments continue, public-health surveillance systems that track and integrate suspected outbreaks, individual illnesses and consumer complaints will be increasingly critical to identify the cause of food product failures. This will allow control programs to be put in place to ensure that food is safe.

Using all the tools of risk management, including the evaluation of food processing and preparation practices, will lead to improved sanitation, changes in manufacturing procedures and better food safety education. Implementing GAPs and HACCP sys- 
tems could even lead to recommendations that include a final kill step for foodborne pathogens. Irradiation or other pasteurization steps may be required for fresh produce and other products in the future. If we do not make these investments in public health surveillance and food safety, the benefits of our fresh and abundant food supply will be, to some degree, offset by the continuing occurrence of preventable foodborne illnesses.

C.W. Hedberg is Associate Professor, School of Public Health, University of Minnesota, Minneapolis. The comments of two anonymous reviewers for California Agriculture were included in this paper, and are gratefully acknowledged.

\section{References}

Bean NH, Goulding JS, Lao C, Angulo FJ 1996. Surveillance for foodborne-disease outbreaks, United States, 1988-1992. MMWR 45 (SS-5): 1-55.

[CDC] Centers for Disease Control and Prevention. 1999a. Foodborne diseases active surveillance network (FoodNet): Population survey atlas of exposures, 1998-1999. Atlanta, GA. www.cdc.gov/ncidod/dbmd/ foodnet/surveys/pop_surv.htm.

CDC. 1999b. Outbreaks of Shigella sonnei infection associated with eating fresh parsley, United States and Canada, July-August, 1998. MMWR 48:285-9.

CDC. 1997. Escherichia coli O157:H7 infections associated with eating a nationally distributed commercial brand of frozen ground beef patties and burgers, Colorado 1997. MMWR 46:777-8.

Cody SH, Glynn MK, Farrar JA, et al. 1999. Ann Intern Med 130:202-9.

[FDA] U.S. Food and Drug Administration 1998. Guidance for Industry; Guide to Minimize Microbial Food Safety Hazards for Fresh Fruits and Vegetables. www.foodsafety.gov/ $\sim$ dms/prodguid.html. $43 p$.

Food Marketing Institute. 2000. 1999 supermarket industry facts overview. www.fmi.org/facts_figs.

Hedberg CW, Angulo FJ, White KE, et al. 1999. Outbreaks of salmonellosis associated with eating uncooked tomatoes: Implications for public health. Epidemiol Infect 122:385-93.

Herwaldt BL, Ackers ML, Cyclospora Working Group. 1997. An outbreak in 1996 of cyclosporiasis associated with imported raspberries. N Engl J Med 336:1548-56.

Hilborn ED, Mermein JH, Mshar PA, et al. 1999. A multistate outbreak of Escherichia coli 0157:H7 infections associated with consumption of mesclun lettuce. Arch Intern Med 159:1758-64.

Hogue A, White P, Guard-Petter J, et al. 1997. Epidemiology and control of egg-associated Salmonella enteritidis in the United States. Rev Sci Tech 16:542-53.

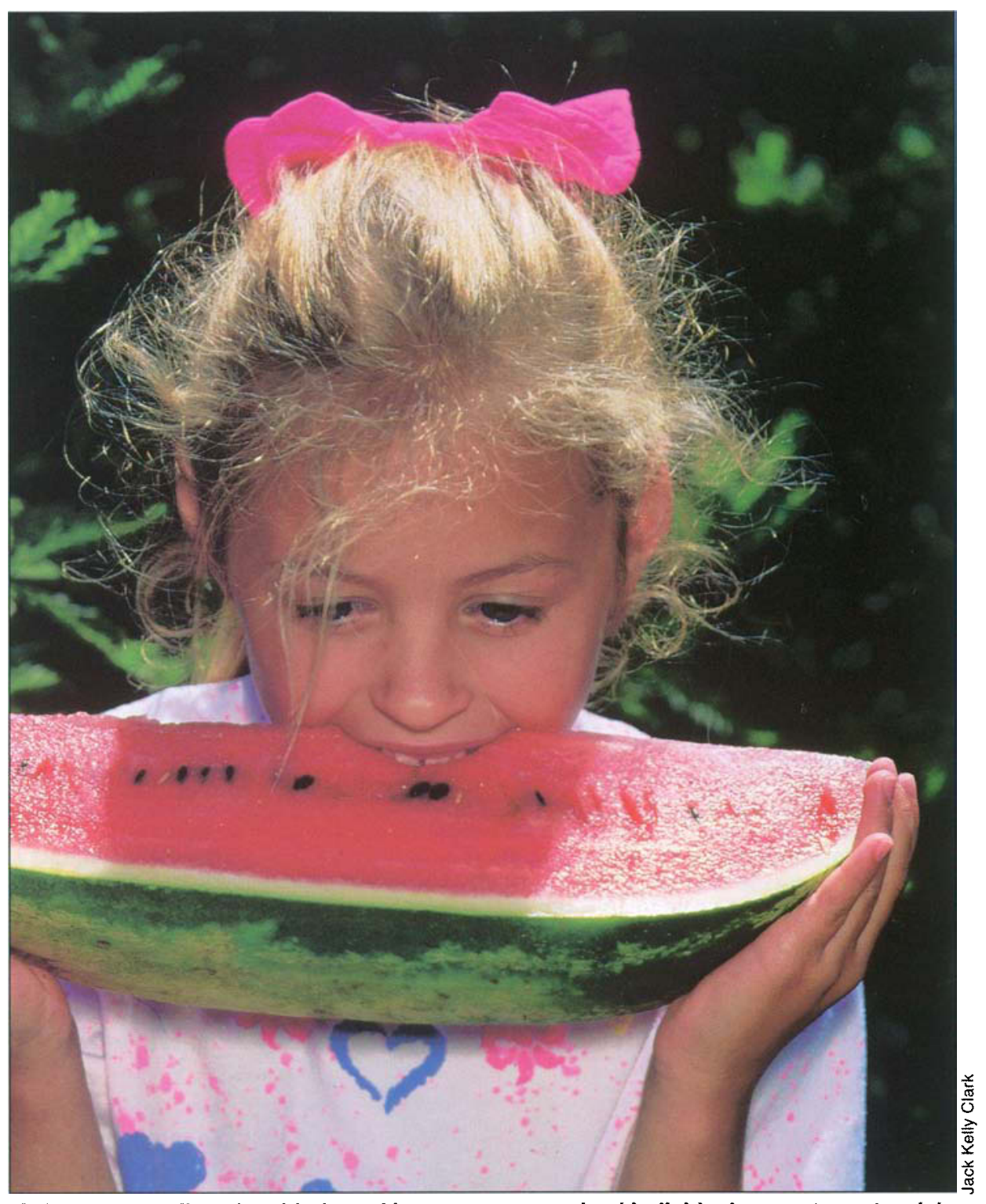

Children, as well as the elderly and immunocompromised individuals, are at greater risk of serious complications from foodborne illness outbreaks. Integrated public-health surveillance systems are needed to track down the causes of iliness and implement safety measures.

Long TC, Edwards DM. 1999. Fresh fruit and vegetable arrival totals for 20 cities, 1998. US Department of Agriculture, Agricultural Marketing Service, Market News Branch. FVAS-3. Mac Kenzie WR, Hoxie NJ, Proctor ME, et al. 1994. A massive outbreak in Milwaukee of Cryptosporidium infection transmitted through the public water supply. N Engl J Med 331:161-7.

Mead PS, Slutsker L, Dietz V, et al. 1999. Food-related illness and death in the United States. Emerg Infect Dis 5:607-25.

National Academy of Sciences. 1982. Diet, Nutrition and Cancer. National Research Council Committee on Diet, Nutrition, and Cancer. Washington, DC. $496 \mathrm{p}$.

Olsen SJ, Mackinnon LC, Goulding JS, et al. 2000. Surveillance for foodborne disease outbreaks, United States, 1993-1997. MMWR 49 (SS-1): $1-51$.
Putnam JJ, Allshouse JE, 1999. Food consumption, prices and expenditures, 1970-1997. US Department of Agriculture, Economic Research Service. Statistical Bulletin No. 965.

Taormina PJ, Beuchat LR, Slutsker L. 1999. Infections associated with eating seed sprouts: an international concern. Emerg Infect Dis 5:626-34

Tauxe R, Kruse $H$, Hedberg $C$, et al. 1997. Microbial hazards and emerging issues associated with produce. A preliminary report to the National Advisory Committee on Microbiologic Criteria for Foods. J Food Protect 60:1400-8.

Thompson B, Demark-Wahnefried W, Taylor $\mathrm{G}$, et al. 1999. Baseline fruit and vegetable intake among adults in seven 5 a-day study centers located in diverse geographic areas. J Am Diet Assoc 99:1241-8. 